www.jmscr.igmpublication.org Impact Factor 5.244

Index Copernicus Value: 83.27 ISSN (e)-2347-176x ISSN (p) 2455-0450 crossref DOI: https://dx.doi.org/10.18535/jmscr/v5i1.18

\title{
Stomach Preserving Surgery in Large Exophytic Gastointestinal Stromal Tumour
}

Authors

\author{
Girish D Bakhshi, Rajesh G. Chincholkar, Chaitanaya G. Patil, \\ Prakash B. Patodekar, Ankush D. Wankhhade, Priyanka M. Saha
}

Department of General Surgery, Grant Government Medical College \& Sir J.J. Group Of Hospitals, Mumbai-08

\begin{abstract}
Gastrointestinal (GI) stromal tumours (GIST'S) are most common sarcomatous tumour of GI tract. They are mesenchymal tumors of the gastrointestinal tract arising from interstitial cells of Cajal. GIST represent ing 0.1-3\% all GI malignancy. ${ }^{(1,2)}$. GIST occur throughout the tubular GI-tract from the lower esophagus to the anus. Stomach is the most common site for GIST. Surgery remains the standard treatment for GIST. We present a case report of 65 years old male presenting with large abdominal lump, later diagnosed as Gastrointestinal stromal tumour and underwent stomach preserving sleeve gastrectomy.
\end{abstract}

\section{INTRODUCTION}

Mazur and Clarke coined the term GIST in 1983 for a distinct set of mesenchymal tumors of the GI tract having no ultrastructural or immunohistochemical features characteristic of smooth muscle differentiation ${ }^{(3)}$.The median age of diagnosis is $60 \mathrm{yr}^{(2)}$. equal in male and female and no racial or ethnic predilections. GISTs now are recognized as a distict group of mesenchymal tumours.GI stromal tumours express kit protein also known as CD117 and is considered as highly specific marker that differentiates GIST from other mesenchymal tumours such as leiomyoma ${ }^{(4)}$.The most common site is stomach (50-70\%), small intestine(25-35\%), colon and rectum (5-10\%), mesentry or omentum (7\%) and oesopahgus $(<5 \%)^{(4,5)}$. GIST most commonly arises from the stomach and accounts for about $1 \%$ of gastric malignancies ${ }^{(1,2)}$. Majority present with an abdominal mass, pain and malena. USG and CT scan show a mass arising from gastric or intestinal wall, displacing adjacent bowel loops ${ }^{(6)}$. Surgery is the main modality of treatment in GIST patients. Imatinib is used in as an adjunct to surgery or in nonresectable tumor. We present a case of Gastric GIST in a 65 yrs old male.

\section{CASE REPORT}

A 65-years old male presented with abdominal lump and vague pain in abdomen on and off since 6 months. There were no other associated general or GI tract symptoms. Clinical examination revealed an averagely built male with pallor. Abdominal examination revealed mobile, firm to hard, non-tender, mass of size approximately $15 \times 8$ $\mathrm{cm}$ occupying the epigastrium, left hypochondrium and extending into left lumbar region.. Rest of the abdominal examination was unremarkable. Routine blood investigations were normal except for low haemoglobin. Ultrasonog-raphy (USG) 


\section{JMSCR Vol||05||Issue||01||Page 15303-15306||January}

showed intraabdominal large heterogenous mass arising from Transverse colon.

Contrast enchanced computerized tomography (CT) of the abdomen reported a large tumor arising probably from the lesser curvature of the stomach size $12 \times 14.3 \times 6 \mathrm{cms}$ displacing the pancreas and spleen reaching anterior abdominal wall (fig 1). USG guided biopsy of patient was suggestive of gastrointestinal stromal tumour. Exploratory laparotomy revealed $20 \times 14 \times 6 \mathrm{cms}$ tumor arising from the greater curvuture of the stomach, exophytically, with a sessile base (fig 2,3). There was no infiltration of the mass into the surrounding structures, nor any evidence of metastases or lymphadenopathy. The tumor was excised with a sleeve of the greater curvature of the stomach and repaired in 2 layers. Postoperative CT-Gastrograffin was suggestive of no leak from stomach. Histopathology of the tumor revealed a 18x15x9 cm sized neoplasm arising from the gastric submucosa composed of spindle shaped and epitheloid cells (fig 4). Mitosis was more than $5 / 50 \mathrm{hpf}$. These findings favoured the diagnosis of gastrointestinal stromal tumor of high malignant potential. The resected margin was reported clear of the tumor. Patient was discharged on imitinab therapy as per medical oncologist. Follow up of 6 month has shown him to be disease and symptom free.

Fig.1 CT scan showing exophytic mass arising from stomach displacing Spleen \& Left Kidney posteriorly

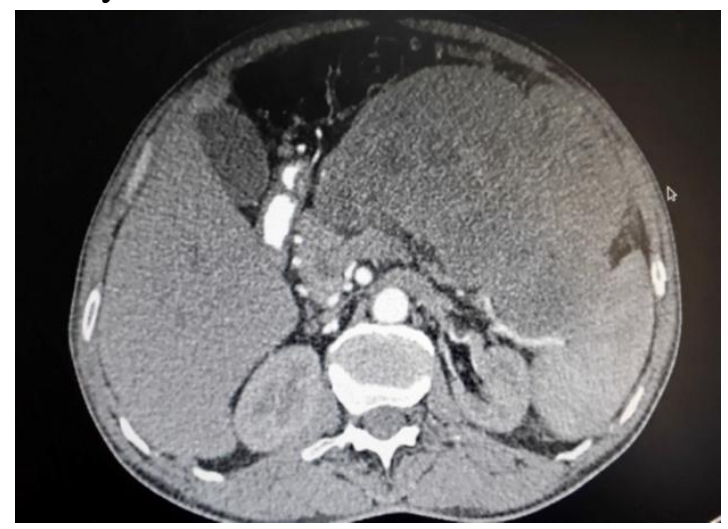

Fig. 2 Intraoperative image showing tumor arising from the greater curvuture of the stomach, exophytically, with a sessile base

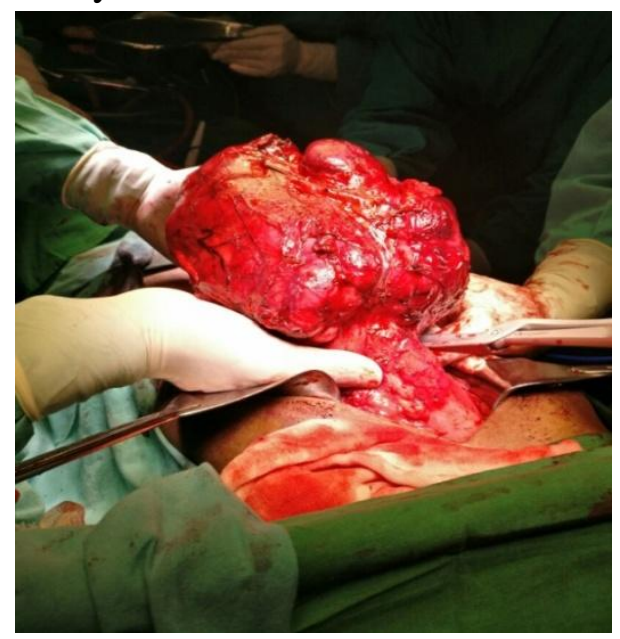

Fig. 3 Receted specimen of Gastric GIST with sleeve of stomach

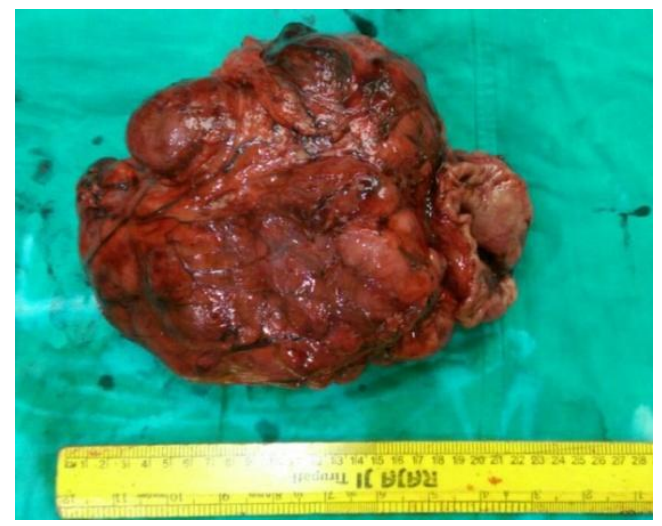

Fig. 4 Histopathology slide showing Spindle cell tumour with spindle cells arranged in Fascicles with spindle shaped elongated nuclei (Hematoxylin \& Eosin stain) 20X

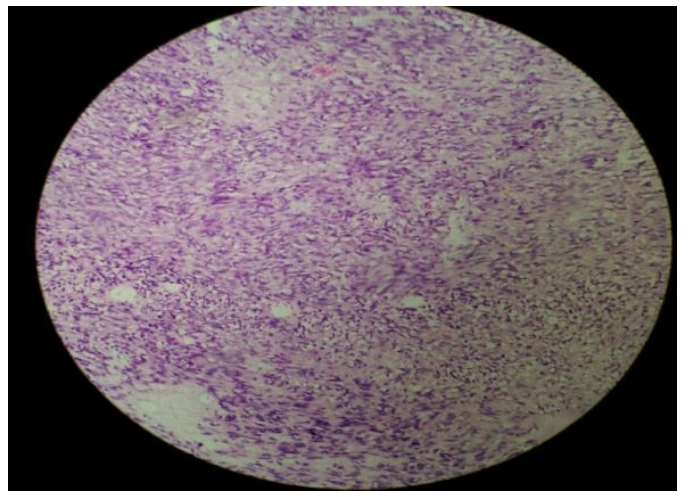

\section{DISCUSSION}

GIST arise from interstitial cell of cajal and are distinct from leiomyoma and leiomyosarcoma which arise from smooth cell. GISTs are now 
defined as cellular, spindle cell, epitheloid or occasional pleomorphic mesencymal tumours of the GIT expressing CD34 and CD117(c-kit) a product of c kit proto-oncogene ${ }^{(7)}$.

Clinical presentation varies from an incidental radiological finding when a patient is investigated for other symptoms to cases of intestinal obstruction, upper or lower GI bleeding or melena, and also as an emergent idiopathic spontaneous intraabdominal hemorrhage. Many of these patients have anemia due to chronic bleeding. Some of these tumors form palpable abdominal masses. GIST are diagnosed generally due to symptoms. In one study $69 \%$ tumour were symptomatic, 21 discovered incidental surgery, $10 \%$ at autopsy ${ }^{(2)}$. In present case patient presented with a large palpable abdominal lump with anemia.

Ultrasonography is often first imaging test used for patient presenting with abdominal lump, however such large tumuor the organ of orgin is unidentifiable and require further investigations.USG report frequently indicates the presence of a huge mass, often filling the abdomen, of heterogeneous reflectivity and frequent necrosis. CT scanning has good sensitivity for the detection of GISTs, and it can show abnormalities in $87 \%$ of cases ${ }^{(8)}$. Larger GISTs with necrosis appear as heterogeneous masses with enhancing borders of variable thickness and irregular central areas of fluid, air, or oral contrast attenuation that reflect necrosis. CT is also sensitive for the detection of metastatic liver, peritoneal, lung, and bone lesions. Imaging studies cannot reliably distinguish benign from malignant GIST unless there is an obvious metastasis or local extension. As in our case Ultrasonography was initially done which was suggestive of large heterogenous mass with solid and cystic component likely arisig from transverse colon. Further evaluation with CECT revealed large exophytic soft tissue mass arising from stomach likely GIST with no liver or peritoneal metastasis or lymphadenopathy. Diagnosis of GIST was confirmed by doing USG guided biopsy of the mass.
Surgical treatment is the only known curative treatment ${ }^{(1,2)}$.The curative intent in the treatment is operative excision with a clear margin, R0 without causing tumour rupture. As GIST does not infiltrate gastric wall, a wide normal mucosa margin is not needed, although some recommend $1 \mathrm{~cm}$ margin, however, microscopic negative margin is sufficient for R0 resection. As rarity of lymphatic dissemination, routine lymphadenectomy is not required. In a series of 140 patients with gastric GIST 68\% wedge resection. $28 \%$ partial gastrctomy, $4 \%$ total gastrectomy was done ${ }^{(9)}$.Wedge or full thickness partial gastrectomy is an effective stratery for tumour that are located along the lesser or greater curvature of stomach (10). Posteriorly based gastric GIST often require transgastric resection through an anterior longitudinal gastrotomy; the tumour is everted and its pedicle divided with a linear stapling device(11).

As in present case patient had only large GIST from stomach with no metastasis or lymphadenopathy, hence excision of tumour along with sleeve of stomach and hand sewen closure in 2 layers was done. Post-operative CT-gastrograffin study was done to rule out any leak from suture line.

The recurrence free survival appears dependent on tumour size, location and mitotic rate(12).One of the earliest schemes of predicting risk factors was stratified by Fletcher et al. in 2002. ${ }^{(13)}$

\section{Scheme of predicting risk factors}

\begin{tabular}{|l|c|c|}
\hline RISK & $\begin{array}{c}\text { TUMOUR } \\
\text { SIZE }(\mathrm{cm})\end{array}$ & MITOTIC COUNT \\
\hline Very low risk & $<2$ & $<5 / 50 \mathrm{HPF}$ \\
\hline Low risk & $2-5$ & $<5 / 50 \mathrm{HPF}$ \\
\hline Intermediate risk & $<5$ & $6-10 / 50 \mathrm{HPF}$ \\
\hline & $5-10$ & $<5 / 50 \mathrm{HPF}$ \\
\hline High risk & $>5$ & $>5 / 50 \mathrm{HPF}$ \\
\hline & $>10$ & Any mitotic count \\
\hline
\end{tabular}

The Histopathology report confirmed the mass as Gastrointestinal stromal tumour with size 18 $\mathrm{x} 15 \mathrm{x} 9 \mathrm{~cm}$ with $>5 / 50 \mathrm{HPF}$ which fall in high risk category.

Guidelines indicate that radical surgical resection is the gold standard for localized primary GIST. Increasing cure rates, overall survival and progression-free survival should be aim of all adjuvant therapy which should be reserved only 
for patient having significant prognostic indicators for disease recurrence. ${ }^{(14)}$. Present case patirnt was started on Imanitib in consultation with oncologist.

\section{CONCLUSION}

The diagnosis of GIST should be considered whenever large mass submucosal in location is seen to arise from stomach. Management of such large GIST should be wide surgical resection followed by tyrosine kinase inhibitors ( Imatinib ) depending on histopathology.

\section{REFERENCES}

1. Crosby JA,Catton CN,Davis A et al.Malignant gastrointestinal stromal tumours of small intestine:a review of 50 cases from a prospective database. Ann surg oncol. 2001;8:50-9

2. Nilsson B,Bumming P,Meis-Kindblom JM,et al. Gastrointestinal stromal tumours: the incidence,prevalence,clinical course and prognostication in preimatinib mesylate era-a population -based study in western Sweden. Cancer.2005;103:821-29

3. Mazur MT, Clark HB. Gastric Stromal Tumours: Reappriasal of Histogenesis. Am J Surg Pathol 1983:7509-19.

4. Miettinem M,Majidi M,Lasota J.pathology and diagnostic criteria of gastrointestinal stromal tumours (GISTs):a review.Eur $J$ Cancer.2002;38:S39-S5.

5. Emory TS,Sobin LH,Lukes L,Lee DH,O' Leary TJ.Prognosis of gastrointestinal smooth-muscle stromal) tumours: dependence on anatomic site.Am J Surg Pathol. 1999;23:82-7

6. Isimbaldi g,Santangelo M,Cenacchi $G$ et al. Gastrointestinal autonomic nerve tumour(plexosarcoma):report of a case with fie needle aspiration biopsy and hstologic, immunocytochemical and ultrastructural study. Acta Cytol 1998;42:189-94
7. Boggino HE, Fernandez MP, Logrono RF. Cytomorphology of gastrointestinal stromal tumor: diagnostic role of aspiration cytology, core biopsy, and immunochemistry. Diagn Cytopathol 2000; 23: 156- 60.8 013;28:441-44

8. Pidhorecky I, Cheney RT, Kraybill WG, Gibbs JF:Gastrointestinal stromal tumors: current diagnosis,biologic behavior, and management. Ann Surg Oncol2000; 7: 705-12.

9. Fujimoto Y,Nakanishi Y,Yoshimura K,Shimoda T. Clinicopathologic study of primary malignant gastrointestinal stromal tumour of stomach with special reference to prognostic factors:analysis of results in 14 surgrical resected patients. Gastric cancer. 2003;6:39-48

10. Cueto J,Vazquez-Frias JA,CastanedaLeder P,Baquera-Heredia J,WeberSanchez A.Laproscopic assisted resection of a bleeding gastrointestinal stromal tumour.JSLS 1999,3:225-28.

11. Morinaga N,Sano A,Katayama K,Suzuki K, Kamisaka K,Asao T,Kuwano II. Laproscopic transgastric tumor- everting resection of gastric submucosal tumour located near esophagogasric junction. Surg Laparosc Endosc Percutan Tech 2004;14:344-48

12. Gold JS ,DeMatteo RP.Combined surgrical and molecular therapy:The gastrointestinal stromal tumour model. Ann Surg .2006;244:176-84.

13. Fletcher CD, Berman JJ, Corless C, Gorstein F, Lasota J, Longley BJ, et al. Diagnosis of gastrointestinal stromal tumors: A consensus approach. Hum Pathol 2002;33:459-65.

14. Casali PG, Blay JY; ESMO/CONTICANET/EUROBONET Consensus Panel of Experts. Gastrointestinal stromal tumours: ESMO Clinical Practice Guidelines for diagnosis, treatment and follow-up. Ann Oncol 2010;21:v98-102. 